\title{
GAMBARAN TINGKAT TEKANAN DARAH PADA KELOMPOK USIA LANJUT ST. MONIKA DI SAMARINDA
}

\author{
Yovita Erin Sastrini \\ Program Studi DIII Keperawatan STIKES Dirgahayu Samarinda \\ Jl. Pasundan No 54 telp/Faks (0541) 748335 \\ y.erinsastrini@yahoo.com
}

\begin{abstract}
ABSTRAK
Tujuan pembangunan kesehatan adalah meningkatkan kesadaran dan kemampuan untuk hidup sehat bagi setiap orang agar terwujud derajad kesehatan masyarakat yang optimal, yang ditandai dengan penduduk yang sehat. Meningkatnya usia harapan hidup manusia Indonesia menjadi 72 tahun, memberikan konsekuensi dengan permasalahannya sendiri dan merupakan pengguna layanan kesehatan paling banyak. Berdasarkan data dari badan pusat statistik (Bapenas) tahun 2019 dalam publikasi statistik penduduk lanjut usia (lansia) 2019 menyebutkan bahwa Kurun waktu hampir lima dekade, prosentase lansia Indonesia meningkat sekitar dua kali lipat (1971-2019), yakni menjadi 9,6 persen (25juta-an) di mana lansia perempuan sekitar satu persen lebih banyak dibandingkan lansia laki-laki (10,10 persen banding 9,10 persen). Pada tahun 2019 sudah ada lima provinsi yang memiliki struktur penduduk tua di mana penduduk lansianya sudah mencapai 10 persen, yaitu: DI Yogyakarta (14,50 persen), Jawa Tengah (13,36 persen), Jawa Timur (12,96 persen), Bali (11,30 persen) dan Sulawesi Barat (11,15 persen). Metode penelitian ini menggunakan analisis statistik deskriptif univaria dan deskripsi bivariat. Analisa data dilakukan secara deskriptif dengan melihat prosentase data yang terkumpul dan disajikan dalam bentuk tabel distribusi frekuensi. Hasil: Rata-rata tekanan darah sistolik tertinggi pada kelompok lanjut usia dan terendah pada kelompok usia pertengahan, rata-rata tekanan darah diastolik tertinggi pada kelompok usia pertengahan dan terendah pada kelompok lanjut usia. Rata-rata tekanan darah sistolik dan tekanan darah diastolik pada kelompok responden yang paling tua yaitu kelompok usia tua, nilainya justru diantara kedua kelompok usia lainnya. Kesimpulan: Berdasarkan data tersebut tidak ada hubungan antara usia dengan tingkat tekanan darah pada manusia usia lanjut yang menjadi responden penelitian ini, yang berarti bahwa para manusia usia lanjut semuanya memiliki risiko yang sama untuk mengalami hipertensi tanpa mengenal klasifikasi usia.
\end{abstract}

Kata Kunci: Tingkat tekanan darah, kelompok usia lanjut

\section{PENDAHULUAN}

Tujuan pembangunan kesehatan adalah meningkatkan kesadaran dan kemampuan untuk hidup sehat bagi setiap orang agar terwujud derajad kesehatan masyarakat yang optimal ,yang ditandai dengan penduduk yang sehat . Masyarakat terdiri dari anak-anak ,remaja ,dewasa dan usia lanjut dengan permasalahan kesehatan masing-masing.

Meningkatnya usia harapan hidup manusia Indonesia menjadi 72 tahun, memberikan konsekuensi dengan permasalahannya sendiri dan merupakan pengguna layanan kesehatan paling banyak. Berdasarkan data Susenas Maret
2019 dalam publikasi statistik penduduk lanjut usia (dalam Bapenas,2019) menyebutkan bahwa selama kurun waktu hampir lima dekade (1971-2019), persentase penduduk lansia Indonesia meningkat sekitar dua kali lipat.Pada tahun 2019, persentase lansia mencapai 9,60 persen atau sekitar 25,64 juta orang. Kondisi ini menunjukkan bahwa Indonesia sedang bertransisi menuju ke arah penuaan penduduk karena persentase penduduk berusia di atas 60 tahun mencapai di atas 7 persen dari keseluruhan penduduk dan akan menjadi negara dengan struktur penduduk tua 
(aging population). Apabila diimbangi dengan kemampuan kelompok lanjut usia yang bisa mandiri, berkualitas, dan tidak menjadi beban masyarakat, maka secara tidak langsung aging population akan memberikan pengaruh positif terhadap pembangunan nasional (https://www.bps.go.id/publication).

Separuh lansia Indonesia mengalami keluhan kesehatan dan persentasenya semakin meningkat seiring dengan bertambahnya umur lansia. Bila dilihat menurut jenis kelamin, keluhan kesehatan pada lansia perempuan (52,31 persen) lebih tinggi persentasenya dibandingkan dengan lansia laki-laki (49,74 persen). Proses penuaan yang terjadi akan berdampak pada berbagai aspek kehidupan, terutama kesehatan. Penduduk lansia secara biologis akan mengalami proses penuaan yang ditandai dengan menurunnya daya tahan fisik. Hal ini dapat menyebabkan tubuh lebih rentan terhadap penyakit tertentu,yang terdeteksi melalui keluhan kesehatan. Hipertensi hinggga saat ini masih menjadi masalah utama di bidang kesehatan ,tidak hanya di Indonesia namun juga diseluruh dunia (Rohman, et all 2011 ).

Organisasi kesehatan dunia WHO mendesak agar seluruh dunia senantiasa mempromosikan pola hidup sehat sepanjang hidup dan menyediakan layanan kesehatan dasar untuk mendeteksi penyakit kronis pada tahap dini sehingga dapat diobati, selain promosi pola hidup sehat perlu dilakukan pemeriksaan tekanan darah maupun penyuluhan tentang hipertensi dan bahayanya secara rutin terutama pada lansia dengan riwayat hipertensi.

\section{METODE}

Variabel dalam penelitian ini adalah variabel independen yaitu tingkat tekanan darah dan variabel dependen yaitu kelompok usia lanjut. Instrumen yang digunakan adalah kuesioner, selain itu subjek penelitian akan dilakukan pengukuran tekanan darah dan setiap responden dilakukan satu kali pengukuran. Jenis penelitian ini merupakan penelitian bersifat deskriptif yang bertujuan untuk mengetahui gambaran tingkat tekanan darah pada kelompok usia lanjut.

\section{HASIL}

Deskripsi Univariat

1. Usia

Responden penelitian ini yang berjumlah 44 orang memiliki rata-rata usia 68,30 tahun dengan standar deviasi 6,94 tahun, responden paling muda berusia 53 tahun dan yang paling tua berumur 84 tahun. Distribusi responden menurut klasifikasi usia disajikan dengan tabel 3.1. Tampak bahwa hanya 6,8 persen tergolong usia pertengahan, sisanya tergolong lanjut usia dan usia tua. Tampak pula bahwa responden yang tergolong lanjut usia adalah jumlah paling banyak yakni hampir 80 persen, dan tidak ada responden tergolong sangat tua.

Tabel 1. Distribusi Responden Menurut Klasifikasi Usia

\begin{tabular}{cccc}
\hline $\begin{array}{c}\text { Klasifikasi } \\
\text { Usia }\end{array}$ & Jumlah & Prosentase & $\begin{array}{c}\text { Persentase } \\
\text { Kumulatif }\end{array}$ \\
\hline Usia & 3 & 6,8 & 6,8 \\
Pertengahan & 35 & 79,6 & 86,4 \\
Lanjut Usia & 6 & 13,6 & 100,0 \\
Usia Tua & 0 & 0,0 & \\
Sangat Tua & & & \\
\hline Total & 44 & 100,00 & - \\
\hline
\end{tabular}

2. Tekanan Darah Sistolik

Tekanan darah (TD) sistolik responden memiliki rata-rata 143,86 mmHg dengan standar deviasi 20,25 mmHg, TD sistolik paling rendah 110 $\mathrm{mmHg}$ dan paling tinggi $200 \mathrm{mmHg}$. 
Jurnal Keperawatan Dirgahayu

Volume 2, Nomor 1, Maret 2020

Tabel 2. Distribusi Responden Menurut Klasifikasi TD Sistolik

\begin{tabular}{cccc}
\hline $\begin{array}{c}\text { Klasifikasi } \\
\text { TD Sistolik }\end{array}$ & Jumlah & Persentase & $\begin{array}{c}\text { Persentase } \\
\text { Kumulatif }\end{array}$ \\
\hline $\begin{array}{c}\text { Normal } \\
\text { Hipertensi } \\
\text { ringan }\end{array}$ & 16 & 36,4 & 36,4 \\
$\begin{array}{c}\text { Hipertensi } \\
\text { sedang }\end{array}$ & 13 & 34,1 & 70,5 \\
$\begin{array}{c}\text { Hipertensi } \\
\text { berat }\end{array}$ & 0 & 0,0 & 100,0 \\
$\begin{array}{c}\text { Hipertensi } \\
\text { sangat berat }\end{array}$ & 0 & 0,0 & \\
\hline Total & 44 & 100,0 & - \\
\hline
\end{tabular}

Tampak pada tabel 3.2 bahwa sebanyak 36,4 persen responden memiliki tekanan darah sistolik tergolong normal, sisanya sebanyak 63,6 persen terpapar hipertensi ringan dan hipertensi sedang. Meskipun tidak ada responden yang terpapar hipertensi berat atau sangat berat, namun berdasarkan rata-rata tekanan darah sistolik sebesar 143,86 $\mathrm{mmHg}$ (termasuk dalam klasifikasi hipertensi ringan), maka dapat dikatakan bahwa secara umum responden terpapar hipertensi ringan dan berpotensi meningkat terpapar hipertensi sedang jika standar deviasi sebesar 20,25 mmHg diperhitungkan.

3. Tekanan Darah Diastolik

Hasil pengukuran tekanan darah diastolik keseluruhan responden memberikan rata-rata sebesar 82,05 mmHg dengan standar deviasi 10,47 $\mathrm{mmHg}$, tekanan darah diastolik yang paling rendah $60 \mathrm{mmHg}$ dan yang tertinggi $110 \mathrm{mmHg}$. Berdasarkan statistik deskriptif tersebut, di mana besaran rata-rata termasuk dalam klasifikasi normal, maka dapat dikatakan bahwa tekanan darah diastolik responden secara umum tergolong normal meskipun standar deviasi diperhitungkan. Kesimpulan deskriptif tersebut didukung oleh besaran persentase pada tabel 3.3, meskipun ada beberapa responden yang terpapar hipertensi ringan dan sedang bahkan ada 1 orang responden yang terpapar hipertensi berat, namun tampak bahwa sebagian besar yakni 72,7 persen responden memiliki tekanan darah diastolik termasuk dalam klasifikasi normal.

Tabel 3. Distribusi Responden Klasifikasi Tekanan Darah Diastolik

\begin{tabular}{lccc}
\hline $\begin{array}{c}\text { Klasifikasi } \\
\text { TD } \\
\text { Diastolik }\end{array}$ & Jumlah & Prosentase & $\begin{array}{c}\text { Prosentase } \\
\text { Kumulatif }\end{array}$ \\
\hline $\begin{array}{l}\text { Normal } \\
\text { Hipertensi } \\
\text { ringan }\end{array}$ & 32 & 72,7 & 72.7 \\
$\begin{array}{l}\text { Hipertensi } \\
\text { sedang }\end{array}$ & 5 & 13,6 & 86,4 \\
$\begin{array}{l}\text { Hipertensi } \\
\text { berat }\end{array}$ & 1 & 2,3 & 97,7 \\
$\begin{array}{l}\text { Hipertensi } \\
\text { sangat } \\
\text { berat }\end{array}$ & 0 & 0,0 & 100 \\
\hline \multicolumn{1}{c}{ Total } & 44 & 100,0 & - \\
\hline
\end{tabular}

B. Deskripsi Bivariat

Pada bagian ini dideskripsikan tekanan darah responden menurut klasifikasi usia.

Tabel 4. Rata-rata Tekanan Darah Responden Menurut Klasifikasi Usia

\begin{tabular}{lcc}
\hline \multirow{2}{*}{$\begin{array}{c}\text { Klasifikasi } \\
\text { Usia }\end{array}$} & \multicolumn{2}{c}{ Rata-rata $(\mathrm{mmHg})$} \\
\cline { 2 - 3 } & $\begin{array}{c}\text { Sistolik } \\
\text { Usia }\end{array}$ & TD Diastolik \\
\hline Pertengahan & 140,00 & 86,67 \\
Lanjut Usia & 144,57 & 81,43 \\
Usia Tua & 141,67 & 83,33 \\
\hline \multicolumn{1}{c}{ Total } & 143,86 & 82,05 \\
\hline
\end{tabular}

Tampak pada tabel 3.3 bahwa rata-rata tekanan darah sistolik tidak ada yang kurang dari $140 \mathrm{mmHg}$ atau tidak ada yang tergolong normal untuk semua klasifikasi usia. Rata-rata tekanan darah diastolik untuk semua klasifikasi usia tampak semuanya kurang dari $90 \mathrm{mmHg}$ atau semuanya tergolong normal. Hal tersebut sesuai dengan kesimpulan deskriptif sebelumnya bahwa berdasarkan tekanan darah sistolik secara umum responden terpapar hipertensi dan berdasarkan tekanan 
darah diastolik responden secara umum tergolong normal.

Mencermati perbedaan rata-rata tekanan darah menurut klasifikasi usia pada tabel 3.3, tampak tidak ada pola linier baik pada tekanan darah sistolik maupun tekanan darah diastolik. Ratarata tekanan darah sistolik tertinggi pada kelompok lanjut usia dan terendah pada kelompok usia pertengahan, rata-rata tekanan darah diastolik tertinggi pada kelompok usia pertengahan dan terendah pada kelompok lanjut usia. Rata-rata tekanan darah sistolik dan tekanan darah diastolik pada kelompok responden yang paling tua yaitu kelompok usia tua, nilainya justru diantara kedua kelompok usia lainnya, dengan demikian, dapat dikatakan bahwa tidak ada hubungan antara usia dengan tingkat tekanan darah pada manusia usia lanjut yang menjadi responden penelitian ini.

\section{PEMBAHASAN}

Hasil penelitian ini menunjukkan bahwa tidak ada hubungan antara usia dengan tingkat tekanan darah pada orang dengan usia lanjut. Kandao, et al (2018) menyatakan bahwa dari hasil penelitian yang dilakukan pada pasien di wilayah Puskesmas Toluaan Minahasa, menunjukan bahwa faktor usia tidak ada hubungan dengan penyebab hipertensi, Sedangkan konsumsi alkohol merupakan faktor dominan yang menyebabkan terjadinya hipertensi.

Hasil penelitian lain yang mendukung penelitian ini adalah penelitian yang dilakukan oleh Brenan, et al (1986) yang menyatakan tidak dapat menunjukkan perbedaan terkait usia dalam variabilitas tekanan darah menggunakan tes ketat (standar deviasi atau koefisien variasi), namun kisaran tekanan darah berbeda pada muda dan tua.

Tidak ada hubungan antara umur dengan tekanan darah pada penelitian ini dapat terjadi karena faktor-faktor yang secara langsung mempengaruhi tekanan darah pada lansia, yaitu; riwayat penyakit, psikologis lansia dan gaya hidup.

Gaya hidup memiliki peran utama untuk mencegah penyakit tekanan darah tinggi, penyakit kardiovaskular dan mengurangi persyaratan untuk terapi obat antihipertensi (Beilin \& Burke, 1999). WHO (2002; Borhani, et al., 2015 dikutip oleh Shafieyan, et al., 2016) mengungkapkan bahwa $80 \%$ dari penyakit jantung dapat dihindari dengan melakukan perubahan pada faktor risiko seperti; pola makan yang buruk, aktivitas yang kurang dan aktivitas fisik yang rendah, serta merokok. Merokok dan hipertensi secara independen terkait dengan peningkatan viskositas darah dan plasma yang lebih tinggi (Levenson, et al, 1987 dikutip oleh Narksawat, 2010)

Akbarpour, et al (2018) mengungkapkan bahwa pada orang yang tidak menggunakan obat antihipertensi, gaya hidup sehat menunjukkan hubungan yang signifikan dengan kontrol hipertensi, dalam hal ini modifikasi gaya hidup perlu dilakukan sebagai tindakan promosi kesehatan yang menekankan pada pengaturan pola diet sehat bagi lansia dalam membantu mengatasi masalah kesehatan, khususnya hipertensi.

\section{KESIMPULAN DAN SARAN}

\section{Kesimpulan}

1. Hasil pengukuran tekanan darah manusia usia lanjut yang menjadi responden penelitian ini, berdasarkan tekanan darah sistolik terindikasi bahwa secara umum responden terpapar hipertensi ringan dan berpotensi meningkat terpapar hipertensi sedang, dan berdasarkan tekanan darah diastolik responden secara umum tergolong normal.

2. Tidak ada hubungan antara usia dengan tingkat tekanan darah pada 
manusia usia lanjut yang menjadi responden penelitian ini, yang berarti bahwa para manusia usia lanjut semuanya memiliki risiko yang sama untuk mengalami hipertensi tanpa mengenal klasifikasi usia.

\section{Saran}

Sebagai implikasi hasil penelitian, dikemukakan beberapa saran sebagai berikut.

1. Bagi individu yang telah berusia 45 tahun keatas hendaknya selalu mengontrol tekanan darah, menghindari makanan atau minuman yang dapat memicu kenaikkan tekanan darah, serta melakukan olah raga yang sesuai secara teratur.

2. Bagi petugas kesehatan hendaknya tidak bosan dan terus menerus mengkampanyekan pola hidup sehat dan mensosialisasikan senam anti hipertensi yang sesuai dengan manusia usia lanjut.

3. Bagi peneliti lain agar lebih menyempurnakan penelitian ini, melibatkan lebih banyak variabel atau faktor risiko hipertensi dalam rangka menekan angka hipertensi di kalangan manusia usia lanjut.

\section{DAFTAR PUSTAKA}

Akbarpour, S., Khalili, D., Zeraati, H. et al. Healthy lifestyle behaviors and control of hypertension among adult hypertensive patients. Sci Rep 8, $8508 \quad$ (2018). https://doi.org/10.1038/s41598-01826823-5

Aspuah S. (2013) Kumpulan kuesioner dan Instrumen Penelitian

Kesehatan. penerbit Nuha medika Yogyakarta.

Agoes.A,dkk,(2008),Penyakit diusia tua ,Penerbit : buku Kedokteran EGC
Brenan, M., O’Brien, E, \& O’Malley, K. (1986). The effect of age on blood pressure and heart rate variability in hypertension. Journal of Hypertension, 4(6), S269-S272.

L. J. Beilin, I. B. Puddey, V. Burke, Lifestyle and hypertension, American Journal of Hypertension, Volume 12, Issue 9, September 1999, Pages 934945, https://doi.org/10.1016/S0895$\underline{\text { 7061(99)00057-6 }}$

Kandou, G. D., Kembuan, I \& Kandou, P. C. (2018), "Obesity and Other Risk Factors Associated with Hypertension in Puskesmas Toluaan of Southeast Minahasa Regency" in The 2nd International Meeting of Public Health 2016 with theme "Public Health Perspective of Sustainable Development Goals: The Challenges and Opportunities in Asia-Pacific Region", KnE Life Sciences, pages 241-249. DOI 10.18502/kls.v4i4.2283

Marya R.K (2013) ,Buku Ajar Patofisiologi, mekanisme terjadinya penyakit ,Penerbit : Bina Rupa Aksara Publisher,Tangerang

Narksawat, et al. (2010). Association between an unhealthy lifestyle and other factors with hypertension among Hill Tribe Populations of Mae Fah Luang Distric, Chiang Ray Province, Thailand. The Southheast Asian Journal of Tropical Medicine and Public Health, 41(3), 726-734.

Notoatmojdo (2012) Metodologi Penelitian Kesehatan. Penerbit :PT. Rineka Cipta, Jakarta.

Perhimpunan dokter spesialis syaraf Indonesia (1999),Buku Ajar 
Neurologi klinis ,Penerbit : Gajah Mada University Press.

Shafieyan, et al. (2016). Association between lifestyle and hypertension in patients referred to health care centers of Ilam City in 2014. Global Journal of Health Science, 8(6), 161-167.

Doi:10.5539/gjhs.v8n6p161.

Widyanto FC\&Triwibowo (2013),Trend Disease (Trend penyakit saat ini), Penerbit : Trans Info Media Jakarta.

Azwar Z. 2003. Sikap Manusia Teori dan Pengukurannya. Penerbit :Pustaka Pelajar Yogyakarta.

Hastono SP. 2011. Statistik Kesehatan, penerbit: PT Rajagrafindo Persada,

Badan Pusat Statistik. (2019). Statistik Penduduk Lanjut Usia tahun 2019. Diambil dari https://www.bps.go.id/publication. Tanggal 29 Februari 2019 jam 19.00 